\title{
XIX. Yüzyılın IIlk Yarısında Habsburg Monarşisi'nin Şark Siyasetine Dair Perde Arkası Tartışmalar
}

\author{
Tuğba İsmailoğlu Kacır* \\ (ORCID ID: 0000-0001-7655-2029) \\ Makale Gönderim Tarihi \\ 03.02.2019 \\ Makale Kabul Tarihi \\ 18.03.2019
}

\section{Özet}

XIX. yüzyıl ile birlikte Osmanlı topraklarında yaşanan Yunan İsyanı (1821-29) ve Mehmet Ali Paşa İsyanı (1831-41), bir anda tüm Avrupa'nın gündemine oturmuş ve Napolyon'un ardından, bilhassa Metternich'in (1773-1859) büyük çabalarıyla yeniden tesis edilmeye çalışılan Avrupa düzeninde bütün taşları yerinden oynatmışlardır. 1815 Viyana Kongre'sindeki uzlaşı gereği, mevcut Avrupa düzenini muhafaza etme amacıyla, yenilikçi ve ayrılıkçı akımlar karşısında tüm monarşilerin desteklenmesi fikri sebebiyle, bir monarşi olan Osmanlı Devleti de Avrupalı monarşiler tarafından desteklenmelidir. Bu dönemde Metternich'in Osmanlı'dan yana tavır alan devlet politikası Şark siyasetini belirleyici olmuş ve bu konu siyasi tarihin önemli başıklarından biri olarak tarihçilerin dikkatini bir hayli çekmiştir. Ancak Metternich'in Osmanlı Devleti'ne dair görüşlerinin nasıl oluştuğu, hangi kaynaklardan beslendiği soruları ise arka planda kalmıştır.

Metternich'in kararlarında danışmanı Friedrich von Gentz'in (1764-1832) büyük etkisi bulunmaktadır. Ancak Osmanlı Devleti ile şahsi hiçbir etkileşimi olmamış ve bu konuda eğitimi bulunmayan Gentz'i kim veya kimler bilgilendirmekte ve yönlendirmektedir? Diğer taraftan Habsburg Devleti'nin Şark siyaseti, dönemin şarkiyatçıları tarafından benimsenmekte midir, yoksa eleştirilmekte midir? Tüm bu soruların cevabı için dönemin şarkiyatçılarının konuya bakışlarına, fikir ayrılıklarına ve hatta aralarındaki ilişki ağına bakmak gerekmektedir. Bu çalışmada bilhassa Gentz, Anton Prokesch von Osten (17951876), Franz von Ottenfels-Gschwind (1778-1851) ve Joseph von HammerPurgstall (1774-1856)'in eserlerinden, hatırat ve mektuplarından faydalanılarak XIX. yüzyılın ilk yarısında Habsburg Monarşisi'nin Şark siyasetinin perde arkasındaki tartışmalar anlaşılmaya çalışılacaktır.

Anahtar Kelimeler: Habsburg, Osmanlı, Şark Meselesi, Metternich, Gentz, Hammer, Prokesch, Ottenfels

* Dr. Öğr. Üyesi, İstanbul Medeniyet Üniversitesi, Edebiyat Fakültesi, Tarih Bölümü, tugbakacir@yahoo.com.

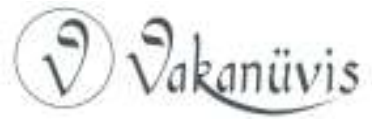




\section{Backstage Discussions on the Eastern Policy of the Habsburg State in the Second Half of the 19th Century}

\section{Abstract}

The Greek Revolt (1821-29) and the Rebellion of Mehmet Ali Pasha (183141), which broke out in the Ottoman Empire, suddenly had been an agenda topic of Europe. And after Napoleon, the European order that Metternich (1773-1859) tried to reestablish with great efforts, turned upside down. Due to the consensus in the 1815 Congress System, to preserve the existing European order, the Ottoman Empire, which was a monarchy, had to be supported by the European monarchies. In this period Metternich's state policy in favor of Ottoman Empire was an important variable in Oriental politics and this issue has attracted the attention of historians as one of the important topics of political history. But the questions, how Metternich's views on the Ottoman Empire formed and from which sources originated, remained in the background.

In Metternich's decisions, his adviser, Friedrich von Gentz (1764-1832) had a great influence. But who does inform Gentz, who has no personal interaction with the Ottoman Empire and no education on this subject? On the other hand, is the Oriental politics of the Habsburg Empire adopted or criticized by the orientalists of the time? For all these questions, it is necessary to look at the perspectives of the orientalists of the period, their disagreements and even their debates. In this study we will try to understand the backroom discussions about the Oriental politics of the Habsburg Monarchy in the first half of the nineteenth century, especially with the help of Gentz's, Anton Prokesch von Osten's (1795-1876), Franz von Ottenfels-Gschwind's (1778-1851) and Joseph von Hammer-Purgstall's (1774-1856) works, memoirs and letters.

Keywords: Habsburg, Ottoman, Eastern Question, Metternich, Gentz, Hammer, Prokesch, Ottenfels.

\section{Giriş}

Dönüşüm yüzyılının önemli aktörlerinden biri olan Metternich, yakın komşusu olan Osmanlı Devleti sınırları içerisinde XIX. yüzyılın ilk yarısında yaşanan isyan ve savaşlarda Osmanlı'dan taraf olmuş ve Avusturya İmparatorluğu'nun Şark politikasını bu tavırla oluşturmuştur. Bu tutumun altında pek çok sebep yatmaktadır. Ancak en dikkat çeken sebep Habsburg Monarşisi'nin Osmanlı Devleti'nin bütünlüğünü

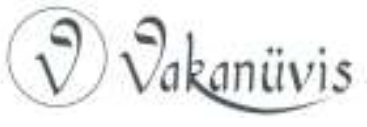


mümkün olduğu kadar korumaya çalışarak diğer Avrupalı devletlerin hemen yanı başındaki topraklarda geniş hâkimiyet alanları elde etmelerinin önüne geçme çabasıdır. Bilhassa Yunan İsyanı ${ }^{1}$ esnasında (1821-29), klasisizm ve romantizm akımlarının etkisi ile köklerini Helenistik kültürde arayan Avrupa'da, Yunanlardan yana tavır koymamış olmak oldukça ilginç görünmektedir. Bir devlet dış politikasına dönüşen Metternich'in bu tutumunun, dönemin entelektüellerinin şahsi mektup ve hatıratlarında ve çeşitli medya organlarında yayınlana(bile)n yazılarında çokça eleştirildiğini görmekteyiz. Bu muhalefete rağmen bu konuda dönemin entelektüelleri arasında da bir birliğin olmadığını ayrıca belirtmek gerekmektedir. Gerek Yunan İsyanı gerek Mehmet Ali Paşa İsyanı (1831-41) Avrupalıların ilgisini oldukça çekmiş, bu iki konu sadece siyasiler için değil, entelektüeller için de önemli bir gündem olmuştur. Bu çalışmada Metternich döneminin önde gelen bazı aktörlerinin birbirleriyle olan kişisel ilişkileri de göz önünde bulundurularak Osmanlı'ya ve Osmanlı sınırları içerisinde gelişen olaylara bakışlarına ve bu eksende ortaya çıkan tartışmalara değinilmiştir.

\section{Friedrich von Gentz ve Metternich Sistemi}

Metternich'in danışmanı olarak pek çok kararın alınması ve uygulanmasında aktif rol oynayan Friedrich von Gentz (1764-1832) "Metternich Sistemi"nin tavizsiz uygulamalarının ardındaki en önemli destekçi olarak karşımıza çıkmaktadır. Kendisini bir politikacı olmanın

\footnotetext{
1 Yunan İsyanı́nın Alman çağdaşları tarafından nasıl değerlendirildiğini takip için bkz.: Karl Mendelssohn Bartholdy, Geschichte Griechenlands. Von der Eroberung Konstantinopels durch die Türken im Jahre 1453 bis auf unsere Tage, C. 1, Paderborn 1870; Prince Richard Metternich, Memoirs of Prince Metternich 1773-1835, Alexander Napier (Çev.), 5 C., Londra 1880-1882; Metternich-Winneburg, Richard (Ed.), Aus Metternich's nachgelassenen Papieren. Geordnet und zusammengestellt von Alfons v. Klinkowström, C. I, Bölüm 1 Viyana 1880; C. I, Bölüm 2, Von der Geburt Metternich's bis zum Wiener Kongress 1773-1815; C. II, Bölüm 1, C. II, Bölüm 2, Friedens-Era 1816-1848, Viyana 1881; Anton Grafen Prokesch-Osten (Ed.), Zur Geschichte der orientalischen Frage. Briefe aus dem Nachlasse Friedrichs von Gentz, 1823-1829, Viyana 1877; Anton Prokesch-Osten, "Betrachtungen über die orientalische Frage", Journal des österreichischen Lloyd, Triest 21. Haziran 1848; Anton Freiherrn von Prokesch-Osten, Geschichte des Abfalls der Griechen vom türkischen Reiche im Jahre 1821 und der Gründung des Hellenischen Königreiches. Aus diplomatischem Standpuncte, C. I, II, Viyana 1867.
}

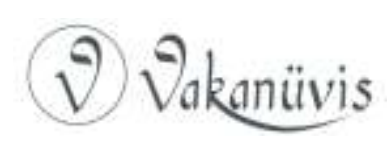


yanında, bir "entelektüel"2 olarak da tanımlayan Gentz'in, yazınsal faaliyetleri gazetecilik alanında toplansa da yaptığı saha okumaları ve pek çok farklı kaynaktan kendisine ulaşan rapor niteliğindeki Şark mektuplarıyla Osmanlı hakkında derinlemesine bilgi sahibi olmaya çalıştı̆̆ını görüyoruz. Ancak tüm bu çabasına rağmen Gentz'in Türklere dair tüm bilgisinin teorik, kendisine aktarılandan ibaret olduğu aşikardır. Şöyle ki Gentz, Ottenfels'e 1826'da yazdığı bir mektupta: "Hiçbir zaman Türklerle doğrudan bir temasta bulunmadım, açıkçası onları daha yakından tanısam sever miyim, nefret mi ederim bilmiyorum." ${ }^{3}$ demektedir.

1764 yılında Breslau'da doğan Gentz Prusya vatandaşı idi ve ilk gençlik yılları Kutsal Roma-Germen Imparatorluğu çatısı altında yaşanan Prusya-Avusturya ikilemi arasında geçti. Königsberg'de Immanuel Kant'tan (1724-1804) ders gören Gentz, sonrasında Prusya Devleti hizmetinde bulundu. Gentz' in, Fransız Devrimi'ne karşı en ciddiye alınan eleştirel çalışmalardan biri olan, Edmund Burke'ün (1729-1797) "Reflections on the Revolution in France" 4 adlı eserini tercümesi siyasi düşünür ve yazar olarak Avrupa'da tanınırlığını arttırdı. Devrimin karşısında ateşli bir modern konservatizm savunucusu olan Gentz, çok geçmeden bu düşüncenin cisimleşmiş hali olan Habsburg İmparatorluğu'nun yönetim kadrolarının ilgisini çekti. ${ }^{5}$

2 Bkz. Gentz'in Philip Henry Earl of Stanhope'a mektubu, Viyana, 19.01.1829 (basılmamış); Kaynak: "Gentz digital":http://gentz-digital.ub.unikoeln.de/portal/databases/id/gentzdigital/titles/id/2629.html?l=de [11.01.2019].

3 Bkz. Gentz'in Ottenfels'e mektubu, Weinhaus, 18.07 .1826 (basılmamış); Kaynak: "Gentz digital":http://gentz-digital.ub.uni-koeln.de/portal/databases/id/gentzdigital /titles/id/1835.html?l=de [11.01.2019]

${ }^{4}$ Edmund Burke, Betrachtungen über die französische Revolution. Nach dem Englischen des Herrn Burke neu-bearbeitet [...] von Friedrich Gentz, 2 Bölüm, Berlin 1793.

${ }^{5}$ Michael Rohrschneider, Friedrich von Gentz (1764-1832) - ein Intellektueller avant la lettre? Beobachtungen anhand der Quellenpublikation "Gentz digital": Leben und Wirken, Kaynak: Gudrun Gersmann, Friedrich Jaeger, Michael Rohrschneider (Ed.), Virtuosen der Öffentlichkeit? Friedrich von Gentz (1764-1832) im globalen intellektuellen Kontext seiner Zeit, historicum-estudies.net, URL: http://www.historicumestudies.net/epublished/virtuosen-der-oeffentlichkeit/digital-intellectuals/friedrichvon-gentz-1764-1832-ein-intellektueller-avant-la-lettre-beobachtungen-anhand-derquellenpublikation-gentz-digital/leben-und-wirken/ [15.03.2019]

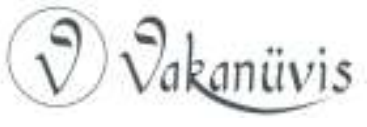


1802 yılından itibaren Avusturya Devleti hizmetine geçen Gentz, Napolyon'a karşı yürütülen dış politikanın medya danışmanlığı görevine getirildikten sonra gelecekte sahip olacağı etkin pozisyon için basamakları çıkmaya başlamıştır. 1815'ten sonra Viyana Kongresi'nin protokol yürütücülüğünü yaparak "Avrupa'nın Sekreteri" unvanını almış ve Metternich ile olan yakınlığı iyice pekişmiştir. 1818'de "Viyana Edebiyat Yıllıkları"nı ${ }^{6}$ kurmuş ve bundan sonra resmi yayın organlarındaki ağırlığı gittikçe artarak Metternich'in propaganda bakanı olarak tanınmıştır.

Fransız Devrimi'nin ardından hızla diğer Avrupa şehirlerinde de yayılan liberal, monarşi karşıtı akımlar karşısında en büyük direnci, Avrupa muhafazakarlığının en önemli kalelerinden birisi olan Habsburg Monarşisi göstermiştir. 11 ulustan müteşekkil bir imparatorluğu yönetmeye çalışan Habsburglar için tüm bu yeni söylemler, mevcut düşmanlarından çok daha büyük bir tehdit oluşturmaktadır. Dolayısıyla önceleri Dış işleri Bakanlığı, ardından Şansölyelik görevlerinde bulunmuş Metternich monarşizmin muhafazası için, içeride ayrılıkçı tüm fikirlere karşı tavizsiz bir kontrol mekanizması kurmuş, dışarıda ise Avrupalı devletleri iş birliği içinde hareket etmeye ikna etmiştir. Gentz ise bu süreçte "Metternich Sistemi" nin en göze çarpan uygulamalarından birisi olan tüm yayın organlarına yönelik sansürün yürütücüsü ve denetleyicisi olarak görev yapmıştır. Metternich'in sağ kolluğunu yaptığı uzun yıllar boyunca liberal ve milliyetçi akımlarla mücadele ederek mevcut Avrupa düzeninin korunması için büyük çaba sarf etmiştir. ${ }^{7}$

\section{Metternich ve Osmanlılar}

Osmanlı ve Habsburg devletlerinin tarihlerinde dikkat çeken bir paralellik mevcuttur. XIII. yüzyılın sonlarına doğru varlık gösteren bu iki devlet, zaman içerisinde komşularının arasından sıyrılarak çok uluslu imparatorluklara dönüşmüşlerdir. Her ikisi de global eksenin Akdeniz'den okyanuslara kayması ile güç kaybetmiş ve XIX. yüzyılın

\footnotetext{
${ }^{6}$ Wiener Jahrbücher der Literatur, 1818-1849.

7 Rohrschneider, Friedrich von Gentz (1764-1832), URL: http://www.historicumestudies.net/epublished/virtuosen-der-oeffentlichkeit/digital-intellectuals/friedrichvon-gentz-1764-1832-ein-intellektueller-avant-la-lettre-beobachtungen-anhand-derquellenpublikation-gentz-digital/leben-und-wirken/ [15.03.2019]
}

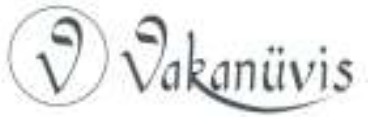


ulusalcı fikirleri karşısında zayıflayarak I. Dünya Savaşı ile nihayete ermişlerdir. Dolayısıyla bu iki çok uluslu imparatorluk arasında bir kaderdaşlıktan söz edilebilir. Lakin XIX. yüzyılda Habsburg Monarşisi'nin, Osmanlı Devleti için de mevcut durumunu muhafaza etmesi yönündeki dış politikasını bu bakışla açıklamak yeterli olmaz. Habsburg için artık bir tehdit oluşturma gücüne sahip olmayan Osmanlı iyi bir komşudur ve Osmanlı topraklarında milliyetçiliğin başarılı olması Habsburg'un Güney Doğu Avrupa topraklarında da bir hareketlenmeye sebebiyet verebilir. Metternich 1841 yılında Prokesch'e yazdığı bir mektupta bu durumu açıkça izah etmektedir: "Benim için Doğu'da yerine getirilmesi gereken görev geçmişte ve bugün hala Türk Imparatorluğu'nun mümkün olduğunca bekasını sağlamaktır. Gerçi bu tavrım Türklere asil bir yaratılıs atfetmemden kaynaklanmıyor, imparatorluğun parçalarının onu kötüye kullanabilecek ellere düşmesini önlemek için bunu yapıyorum. Imparatorluğun Osmanlı ya da Arap olmasını umursamıyorum, ama kesinlikle Rus ya da Fransız olmamalı. Aynı şekilde imparatorluğun küçük parçalara ayrılması da iyi sonuçlar doğurmayacaktır. Çünkü bu küçük parçalar birleşerek, bugünkü Helen Kralığı'ndan ${ }^{8}$ çok daha kötü yapılar oluşturacaklardır." ${ }^{9}$ Metternich, Imparatorluğu'nun doğusunda kalan topraklarda ne Rus hâkimiyetinde bir Yunan Devleti ne de Fransız destekli bir "Muhammed Ali" devleti istiyordu. Osmanlı Devleti'nin Avrupa'daki topraklarını kaybetmesi Rusya'nın bölgede etkinliğini arttırması anlamına gelebilirdi ve bu durum hem Avusturya'nın hem de güçler dengesine zarar vereceği için diğer Avrupalı devletlerin işine gelmezdi.

Metternich, güçler dengesini muhafaza etmeye çalışırken aldığı bu kararları sadece masa başı teorik yaklaşımlar üzerinden değil, Şark'tan

\footnotetext{
${ }^{8}$ Metternich "Helen Krallı̆ı"” ile yeni kurulan Yunan Devleti'ni kast etmektedir. Zaten mektubun muhatabı olan Prokesch, bu dönemde Atina'da Avusturya elçisi olarak Yunan Devleti'nin iç düzenini sağlamaya yönelik çabalarda bulunmaktadır. XIX. yüzyılda Metternich denge siyasetinin bir tezahürü olarak, Güney Doğu Avrupa'daki yeni ulus devletlerin ve bilhassa Yunanistan'ın inşa sürecinde, Rusya'nın bölgedeki ağırlığının önüne geçmek adına diğer Avrupalı devletler tarafından Habsburg Devleti'nin önünün açıldığını söyleyebiliriz. Bu sebepten mevzu bahis mektuplarda Yunan Devleti'nin iç sorunlarının çözüm arayışlarına çokça şahit oluyoruz.

9 “Metternich'in Prokesch'e Mektubu", 9 Ocak 1841, Anton Grafen Prokesch-Osten (Ed.), Aus dem Nachlasse des Grafen Prokesch-Osten. Briefwechsel mit Herrn von Gentz und Fürsten Metternich, Viyana 1881, 2. C., S. 205-6.
}

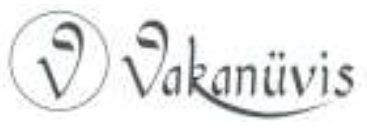


kendisine düzenli olarak gönderilen mektupları ve raporları analiz ederek veriyordu. Bu bilgiler tek bir kaynaktan gelmemekle birlikte, Avusturyalıların yanında Prusyalı elçi ve seyyahlar da Metternich'i Osmanlı topraklarındaki gelişmeler konusunda bilgilendiriyorlardı ${ }^{10}$. Ayrıca İmparatorluğun doğusundaki gelişmeler tüm Avrupalıları yakından ilgilendirdiği için, Osmanlı topraklarındaki gelişmeler akşam yemeklerinin ve salon toplantılarının en gözde konuları arasında yer alıyordu. XIX. yüzyılın ilk yarısında Yunan İsyanı ve klasisizm büyüsüne kapılmış Antik Yunan ilgisi entelektüel sohbetlerin vazgeçilmez konusu idi. Kavalalı Mehmed Ali Paşa ise "Muhammed Ali" olarak Batılı entelektüellerin gözünde çok yakından tanıdıkları bir kahraman, bir özgürlük savaş̧̧ısı idi. Bugünden bakıldığında ilginç görünse de başkent Viyana'nın sohbetlerinde Osmanlı Devleti'nin akıbeti ile ilgili haberlerin heyecan verici dedikodu malzemesi olarak tüketildiğini görüyoruz. Hatta bu ilgi ile somut olarak Metternich'in mektuplarında bile karşılaşıyoruz: "Bugün pek çok kişi soruyor: "Şimdi Türk Imparatorluğu ile ne yapacaksınız?" Benim cevabım kısa oluyor: "Biz onu kendi canlılığında koruyacağız ve ona dışarıdan müdahale olmasını önleyeceğiz." Biz Doğu'nun aydınlanmasını düşünmüyoruz, çünkü devletler yabancı tohumla gelişmiyorlar. (...) Biz bu imparatorluğun mümkün olduğu kadar yaşamasını istiyoruz."11 Metternich'e yakın olup onunla aynı görüşleri paylaşan Anton Prokesch von Osten ve Franz von OttenfelsGschwind gibi isimler onun yanında yer alırken pek çok entelektüel bu görüşlere muhalefet ediyordu. Sesleri bastırılmaya çalışılan bu muhalif kanadın en dikkat çeken temsilcisi Joseph von Hammer-Purgstall ise Metternich'in Şark siyasetini şiddetle eleştiriyordu.

\section{Üç Oryantalistin Siyasete Yön Verme Çabaları}

Joseph von Hammer-Purgstall (d. 1774) ve Franz von OttenfelsGschwind (d. 1778) ${ }^{12} \ldots$ Bu iki oryantalist Şark Akademisi'nde aynı

\footnotetext{
${ }^{10}$ Miroslav Šedivý, "Metternich and the Ottoman reform movement", European Review of History: Revue européenne d'histoire, 18:4, 2011, S. 428.

${ }_{11}$ Metternich'in Prokesch'e Mektubu, 9 Ocak 1841, Viyana, Anton Grafen ProkeschOsten (Ed.), Aus dem Nachlasse des Grafen Prokesch-Osten. Briefwechsel mit Herrn von Gentz und Fürsten Metternich, Viyana 1881, 2. C., S. 205-6.

12 A. Breycha-Vauthier, Ottenfels-Gschwind, Franz Frh. von (1778-1851), Diplomat, Österreichische Biographische Lexikon (ÖBL) 1815-1950, C. 7 (1977), S. 269; Ayrıca
}

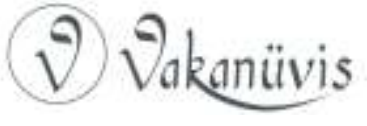


dönemde eğitim aldıkları için öğrencilik yıllarında yakın arkadaştılar. Ancak eğitimlerinin ardından İstanbul'a gönderildiklerinde, dönemin Avusturya İstanbul elçisi Stürmer ${ }^{13}$ ile Hammer arasında yaşanan gerilimlerde Ottenfels'in Stürmer'in yanında yer alması ve hatta Hammer'in ifadesiyle, "onu arkasından vurması"14 yüzünden aralarında büyük bir husumet oluştu. Bu gerginlik yıllar geçtikçe, ikisinin de talip oldukları pozisyonlar çakıştıkça ve bu mücadeleden hep Ottenfels galip çıktıkça daha da arttı. Öyle ki Hammer 1806 'da elçi Stürmer ile yaşadığı gerginliklerin ardından Yaş'a sürülürken Ottenfels İstanbul'da kalmaya devam etti. Düşmanı olarak gördüğü Ottenfels'in "Metternich Sistemi"nde gittikçe yükselmesinin ve sözünün dinlenir olmasının Hammer'i çok kızdırdığını görüyoruz. Şimdilerde düşman olan bu iki eski dostun kaderlerinin, Ottenfels'in Hammer'in önünü kesecek pozisyonlara getirilmesiyle daha pek çok kez çakıştığına tanıklık ediyoruz. Örneğin Napolyon ordusunun Viyana kütüphanelerinden çok sayıda elyazması eseri Paris'e götürmesinin ardından Hammer, bu eserleri geri almak için çok çaba sarf etmiş, 1809'da Metternich'ten resmi görevle Paris'e giderek kitaplar için mücadele etme fırsatı istemişti. Bu talebinin geri çevirmesi üzerine Hammer, resmi görevden vaz geçerek oryantalist sıfatıyla gitmek için müsaade alabilmişti. ${ }^{15}$ Ardından Hammer'in 6 ay boyunca gösterdiği çaba sayesinde Paris'te bulunan eserlerin bir kısmı iade edilmişti. Geride kalan bazı eserler ise ancak iki ülkenin ilişkilerinin düzelmesinin ardından, 1814'te alınabilmiş ve bu görev, en çok kendisinin hak ettiğini düşünen Hammer'e değil, can düşmanı olarak betimlediği Ottenfels'e verilmişti. Paris'teki tüm girişimlerinin böylesine görmezden gelindiği ve çabalarının hasılatını

\footnotetext{
bakınız: Josef Krauter: Franz Freiherr von Ottenfels. Beiträge zur Politik Metternichs im griechischen Freiheitskampfe 1822-1832. Nach ungedruckten Quellen dargestellt, Salzburg 1913; Miroslav Šedivý, Metternich, the Great Powers and the Eastern Question, Pilsen 2013.

13 Ignaz Lorenz Freiherr von Stürmer (1752-1829)

${ }^{14}$ Joseph Freiherr von Hammer-Purgstall, „Erinnerungen aus meinem Leben “, Avusturya Bilimler Akademisi Arşivi, Defter 60, S. 7-9. Hammer'in hatıratı da internete ortamına aktarılmıştır. Bkz: Walter Höflechner; Alexandra Wagner (Ed.), "Joseph von HammerPurgstall. Erinnerungen und Briefe", Version 1 201107: Briefe von 1790 bis Ende 1819, 3 C., Graz 2011. [http://gams.uni-graz.at/context:hp]

${ }^{15}$ Hammer'in Paris seyahati için bkz: Hammer Hatıratı, Defter 78, S. 13-16; Defter 79, S. $11 ; 21-23$.
}

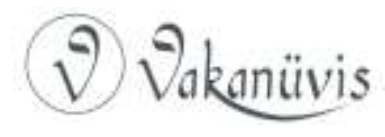


toplayanın, bununla övgüler alanın Ottenfels olduğu düşüncesinin Hammer'i çokça öfkelendirdiğini görüyoruz ${ }^{16}$. Hammer'le Ottenfels arasındaki gerginlik bununla da kalmadı. Hammer'in yaş olarak da büyük olduğu Ottenfels'ten daha donanımlı olduğunu ve Türkleri herkesten iyi tanıdığını düşündüğüne, diplomatik kariyerinin yanında bir oryantalist olarak da ilmi çalışmalarını sürdürdüğü için kendisini üstün gördüğüne şahit oluyoruz. Dolayısıyla ona göre, İmparatorluğun Şark siyaseti oluşturulurken ve uygulanırken onun görüşlerine danışılmalı ve kendisine bu konuda hizmet etme fırsatı verilmeliydi. Ancak Hammer, gerek siyasete uygun olmayan çabuk parlayan yapısı, gerek Metternich ile taban tabana zıt olan görüşleri ${ }^{17}$ sebebiyle gittikçe aktif siyasetin dışına itildi ${ }^{18}$. Hammer'e göre yıkılması çok yakın olan ve kurtarılması artık mümkün olmayan Osmanlı Devleti, Yunanlara barbarca davranıyor ${ }^{19}$ ve bu ortamda Metternich, azılı Yunan düşmanı olan Gentz ve Prokesch'in söylediklerinden başka bir şey duymuyordu.

Muhtemelen bu çatışmalardan dolayı Hammer'in Dış İşleri Bakanlığı'ndaki tercümanlık görevinde, sadece önemsiz postaları görebilmesine ve tercüme etmesine izin veriliyordu. Hatta Gentz tarafından "fitne çıkartıcı, çevresindeki insanların ahlakını bozucu olduğu düşüncesiyle" 20 sadece kısmî zamanlı olarak Bakanlığa gelmesi uygun görülmüştü. Tüm bu olumsuz ortamda gittikçe marjinalleşen Hammer'in, artık her gelişmeyi şahsi algıladığını ve iki devlet arasındaki siyasi gelişmeleri değerlendirirken duygularının etkisinde kaldığını görüyoruz. Hammer ile Ottenfels ve dolayısıyla Hammer ile Gentz ve Metternich arasındaki gerilim, Ottenfels'in 1822' de İstanbul elçisi olarak görevlendirilmesiyle zirveye ulaştı. Hammer bu atamayı kendisine

\footnotetext{
16 Hammer Hatıratı, Defter 93, S. 24.

${ }^{17}$ Hammer Hatıratı, Defter 90, S. 23-24.

18 Harald Heppner, "Hammer Purgstall und österreichische Innenpolitik", Domus Austriae. Eine Festgabe für Hermann Wiesflecker zum 70. Geburtstag, Walter Höflechner; vb. (Ed.), Graz 1983, S. 210; Harald Heppner, "Hammer-Purgstall und die Orientfrage", Österreichische Osthefte, C. XXI., 1979. Viyana; Zürich, S. 89.

${ }^{19}$ Hammer Hatıratı, Defter 123, S. 3.

${ }^{20}$ Gentz' in Joseph Anton von Pilat'a mektubu, Verona 05.12.1822 (basılmamış); Kaynak: "Gentz digital": http://gentz-digital.ub.uni-koeln.de/portal/databases/id/gentzdigital/ titles/id/2525.html?l=en [11.01.2019]
}

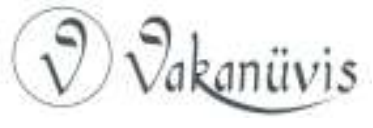


yapılmış bir hakaret olarak algıladı. ${ }^{21}$ Çünkü İstanbul elçisi olmak Hammer'in en büyük hayaliydi. Dolayısıyla Hammer'in kendisine çizdiği siyasi kariyer başarısız oldukça Osmanlı Devleti'ne, Yunan İsyanı'na, Mısır İsyanı'na olan farklı bakış açıları kişisel husumetler yüzünden daha da keskinleşmiş olmalıdır. Bu sebepten Prokesch-Osten da dâhil olmak üzere bu kişilerin mektuplarında, hatıratlarında, kitaplarında ve özellikle dönemin gazetelerinde yazdıklarını bu ilişkiler ışığında okumak gerekir. Aralarındaki şahsi çekişmelerin siyasi görüşlerine büyük oranda yansıdığı görülmektedir.

1795 Graz doğumlu Anton Prokesch ${ }^{22}$ ise asil bir aileden gelmeyen, 1812 'de hukuk eğitimini yarıda bırakarak Napolyon Savaşlarına katılan ve gösterdiği üstün başarılar ve sadakat ile askeriyede şaşırtıcı bir hızla yükselen bir asker bürokrattır. Viyana'da kendisine geniş bir çevre edinen Prokesch kısa zamanda asillerin halkasına dâhil olmayı başarmıştır. Zaten daha sonra yaptığı hizmetlerden dolayı kendisine Leopold nişanı verildiğinde unvan olarak "Doğu'lu" anlamını taşıyan "von Osten"ı seçecektir. Aslında Prokesch, Hammer'in Viyana'daki arkadaş çevresine dâhildir ve aralarında Ottenfels'le olduğu gibi bir düşmanlık söz konusu değildir. Prokesch'in günlüklerinden sık sık Hammer'le görüştüğünü ya da aynı sohbet halkası içinde bulunduğunu takip edebiliyoruz ${ }^{23}$. Muhtemelen Prokesch, yıllar içinde değişen görüşleri dolayısıyla ve Ottenfels'le olan yakınlaşmasının ardından Hammer'den uzaklaşmış olmalıdır.

Prokesch Doğu'ya ilk kez 1824'te donanmada görev alarak gider ve diplomatik kariyeri böylelikle başlamış olur. Gentz'in ve o sıralar İstanbul elçisi olan Ottenfels'in himayesine sahip olan Prokesch kısa sürede

\footnotetext{
${ }^{21}$ Hammer'in Ottenfels'in İstanbul elçisi olarak atanmasının ardından yaşadığı yıkım ve duyguları için ayrıntılı olarak: Hammer Hatıratı, Defter 22, S. 15-24.

22 Bkz: Allgemeine Deutsche Biographie (ADB) C. 26, S. 631-645; Daniel Bertsch, Proeksch von Osten, Anton Franz Graf, Neue Deutsche Biographie (NDB) C. 20, Berlin 2001, S. 739-740.; Constantin von Wurzbach, Biographisches Lexikon des Kaiserthums Oesterreich, Viyana 1856, C. 23, S. 349-356.; Karl Vocelka, Prokesch von Osten, Anton Gf., ÖBL C. 8, S. 301-302.

${ }^{23}$ Bkz: Graf Anton Prokesch von Osten, Aus den Tagebüchern des Grafen Prokesch von Osten (1830-1834), Viyana 1909.
} 
Metternich'in de dikkatini çeker. ${ }^{24}$ Askeri görevle çıktığı seyahatleri esnasında sadece askeri raporlar vermekle yetinmez, bulunduğu yerleri bir oryantalist merakı ile inceler ve tuttuğu seyahat notlarını yayınlar. "Mısır ve Anadolu Hatıraları"25, "Nil Kanalları Arasındaki Topraklar"26, "Kutsal Topraklara Yolculuk"27 ve üç ciltlik "Şark'tan Anılar ve Hatıralar"28 adlı kitapları yayınlandıkları dönemde büyük ilgi görmüştür. Şiirler, soneler ve edebi tasvirlerle dolu eserleri coğrafi, arkeolojik, etnografik ve tarihi ayrıntılarla dolu olduğu için sahada önemli bir boşluğu doldurmuş ve Prokesch'e hatırı sayılır bir saygınlık kazandırmıştır. Bu saygınlık ona diplomatik görevlerin de kapısını açmış, yönetimde olan siyasilerle olan yakınlığının da avantajıyla 1831'de italya'ya sıra dışı elçi, 1834'den sonra da Atina'ya elçi olarak gönderilmiştir. Mart ihtilali'nin (1848) ardından Metternich azledilse de Prokesch aktif olarak diplomaside görev yapmaya devam etmiştir. Hatta 1867-71 arası İstanbul elçiliği görevinde de bulunmuştur. ${ }^{29}$ Yunan ve Mehmed Ali Paşa İsyanlarında Prokesch'in verdiği raporlar büyük önem arz etmiştir.

Alman klasisizminin takipçisi olan Prokesch, insanlık ve sanat için hakiki yol göstericinin Klasik Antik Çağ olduğunu düşünen bir Philhellenist olarak Yunan İsyanı'nın çıkmasının ardından hemen kendisinin o bölgede görevlendirilmesini talep etmiştir. Ancak Prokesch'in Yunan idealizmine olan inancının, bölgeyi, insanlarını, Yunan İsyanı esnasındaki iç çekişmeleri ve hesaplaşmaları gördükçe kaybolduğunu görüyoruz. Zamanla Prokesch'in Yunanlılara karşı eleştirileri gittikçe artar ve kurulacak olan Yunan Devleti'nin varlığını

\footnotetext{
24 Peter Melichar, "Metamorphosen eines treuen Dieners", Bürger zwischen Tradition und Modernität, Robert Hoffmann (Ed.), Wien; Köln; Weimar 1997, S. 114-121.

${ }^{25}$ Graf Anton Prokesch von Osten, Erinnerungen an Ägypten und Kleinasien (1829-31), Viyana 1831.

${ }^{26}$ Graf Anton Prokesch von Osten, Das Land zwischen den Katarakten des Nil, mit einer Karte., astronomisch bestimmt und aufgenommen im Jahre 1827, Viyana 1831.

${ }^{27}$ Graf Anton Prokesch von Osten, Reise ins Heilige Land im Jahr 1829, Viyana 1831.

28 Graf Anton Prokesch von Osten, Denkwürdigkeiten und Erinnerungen aus dem Orient, 3 C., Stuttgart 1836-1937.

29 Selçuk Ünlü, “Avusturya'lı Diplomat Anton Von Prokesch-Osten (1795-1876) ve Türkiye", Türk Dünyası Araştırmaları, 1984, C. 33, S. 57-59.
}

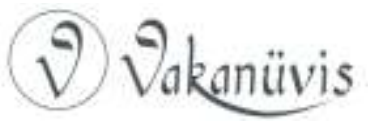


sağlıklı bir şekilde yürütebileceğini düşünmemeye başlar. ${ }^{30} \mathrm{Bu}$ yeni görüşlerini Metternich ve Gentz'e de bildirir. Aslında Prokesch'in düşüncelerinin bu yönde değişmesi çok şaşırtıcı değildir. Temelde zaten Napolyon'a karşı Avusturya ordusunda savaşmak için okulunu bırakan, monarşinin her ne pahasına olursa olsun korunması gerektiğini düşünen muhafazakâr bir Metternich bürokratının sahip olabileceği, hatta olması gereken bakış açısı budur. Bu yaklaşımıyla Prokesch Metternich'in tam arzuladığı bir diplomat olmuş olmalıdır. Prokesch'in 1825-1830 yılları arasında Yunan İsyanı hakkında Metternich'e gönderdiği 80 mektup ${ }^{31}$ bu bakış açısıyla bölgedeki gelişmeleri rapor etmesi açısından çok önemlidir. Prokesch'in düşünceleri Osmanlı topraklarında geçirdiği yıllarla birlikte gittikçe Osmanlı lehine dönmüş, mektuplarında ve kitaplarında "bizi çok hoşnut etmese de onurlandırmasa da bunlar hakikatler"32 diyerek Osmanlı topraklarında şahit olduğu Türkleri öven olayları anlatmıştır.

Dönemin aktörleri arasındaki tüm bu ilişki ağını, bugün takip etmemizi mümkün kılan en önemli kaynak mektuplardır. Prokesch'in mektuplarının çoğu ölümünün ardından, 1870-80'li yıllarda varisleri tarafından yayımlanmıştır. Hammer de mektuplarını hatıratına bir ek olarak tasnif ederek gelecek nesiller için saklamıştır. Gentz' in mektupları ise, hayatının büyük kısmını Gentz'in mektuplarını ve yazışmalarını toplamaya adamış Alman tarihçi ve politikacı Günter Herterich (19392014) tarafından bir araya getirilmiş ve bu zahmetli çalışmanın sonunda siyasi ve entelektüel tarih çalışmaları için çok kıymetli bir koleksiyon oluşmuştur. Köln Üniversitesi ve Şehir Kütüphanesi'ne aktarılan Herterich'in arşivi 2016 yılında "Gentz Digital"33 adı altında internet ortamına aktarılarak tüm araştırmacıların hizmetine sunulmuştur. Bu arşivde Ottenfels'den Gentz'e gönderilen 5, Gentz'den Ottenfels'e

\footnotetext{
30 Ariadni Moutafidou, "Anton Graf Prokesch Osten: Philhellenismus und absolutistisches Staatsbild", Evangelos Konstantinou (Ed.), Das Bild Griechenlands im Spiegel de Völker (17. Bis 20. Jahrhundert), Frankfurt am Main 2008, S. 204.

${ }^{31}$ Daniel Bertsch, "Der österreichische Diplomat Anton Prokesch von Osten (1795-1876) und das heilige Land", Sabina Rogge (Ed.) Zypern und der Vordere Orient im 19. Jahrhundert. Die Levante im Fokus von Politik und Wissenschaft der europäischen Staaten, Münster 2009, S. 45.

32 Ritter von Prokesch A. Osten, Reise ins Heilige Land. Im Jahr 1829, Viyana 1831, S. 53.

${ }^{33}$ gentz-digital.ub.uni-koeln.de
}

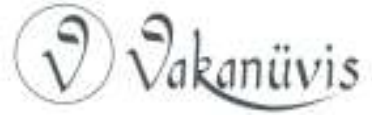


gönderilen 269 mektup bulunmaktadır. Mektupların tarihlerine bakıldığında Ottenfels' in İstanbul elçisi olduğu dönemde, bilhassa 18231831 arası Gentz'in Ottenlfels'e yılda ortalama 30 mektup yazdığını söyleyebiliriz. Ottenfels'in mektuplarının çoğu elimizde olmasa da aşağı yukarı aynı sayıda mektubun da Ottenfels'den geldiğini tahmin etmek mümkündür. Gentz'in mektuplarını "Şark Meselesi'nin Tarihi"34 adı altında yayımlayan Prokesch'in kitabında Ottenfels'den Gentz'e gönderilmiş mektupların 35 tanesi neşredilmiştir. Bu mektupların dikkat çeken yönü ise resmi prosedürden, dolayısıyla sansürden ayrı tutulmuş olmalarıdır ${ }^{35}$. Yazarlar bu sebepten rahat olduklarını, birbirleri ile tüm fikirlerini açık yüreklilikle paylaştıklarını zaman zaman mektuplarında ifade etmektedirler. Gentz'in Doğu'daki diğer bilgi kaynağı olan Prokesch'le olan yazışmalarına bakıldığında, orada da ciddi bir yekûn olduğu söylenebilir. Prokesch'ten gelen mektuplardan sadece 3'ü "Gentz Digital"da bulunmakla birlikte, Gentz'den Prokesch'e yazılan mektupların 124'ünün bu platformda mevcut olduğunu ve bunlardan 63 tanesinin 1831 yılında yazıldığını görüyoruz. Prokesch'in Gentz'e yazdığı mektupların çoğu da halen mevcuttur ve Prokesch'in terekesinde 128 tanesi bulunmaktadır. Prokesch'in Atina sıra dışı elçisi olduğu dönemde yazılan bu mektupların ana teması Yunanistan'ın iç karışıklıklarıdır. Elbette Hammer bu yoğun haberleşme ağının dışındadır. Arşivde Gentz'den Hammer'e gönderilmiş sadece 5 mektup mevcuttur. Bunlar da ya zorunlu kutlama amaçlı kısa mektuplardır, ya da Ottenfels'in İstanbul elçisi olmasının ardından Hammer'in itirazlarını sakinleştirmeye çalışan mektuplardır.

\section{Sonuç}

Tüm bu ilişkiler ağına uzaktan baktığımızda, Habsburg Devleti'nin Şark siyasetine dair büyük bir kutuplaşma olduğunu görüyoruz. Siyasi erki elinde tutan Metternich'in etrafındaki oryantalistlerin de Metternich'in siyasetini destekler raporlar, mektuplar yazdıklarını, ancak yönetimin uzağında olan entelektüel ortamlarda bu siyasetin

\footnotetext{
${ }^{34}$ Anton Grafen Prokesch-Osten (Ed.), Zur Geschichte der orientalischen Frage. Briefe aus dem Nachlasse Friedrichs von Gentz, 1823-1829, Viyana 1877.

35 Gentz'in Ottenfels'e mektubu, Viyana 01.06.1824 (basılmamış); Kaynak: "Gentz digital":http://gentz-digital.ub.unikoeln.de/portal/databases/id/gentzdigital/titles/id/3419.html?l=en[11.01.2019]
}

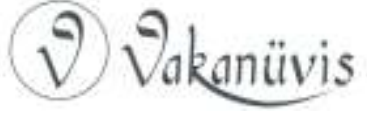


benimsenmediğini söyleyebiliriz. Salon toplantılarında, artık miadını tamamlamış, arkaik Osmanlı'nın sonunun geldiği, dolayısıyla küçük ulusların bağımsızlıkları için desteklenmeleri gerektiği ve Osmanlı sultanlarının yerine çok daha cazip, yüzü batıya dönük bir figür olan Mehmed Ali Paşa'nın eliyle otantik doğunun yeniden canlanmasının sağlanabileceği düşüncelerinin dile geldiğine şahitlik ediyoruz. Ancak "Metternich Sistemi”nin şedit sansürünün, tüm bu düşüncelerin basına yansımasını önlemeye çalıştığını dönemin hatıratlarından öğreniyoruz. Habsburg Monarşisi'ni yenilikçi fikir akımları karşısında korumaya yönelik olan sansür uygulamasının hemen her konuya müdahil olduğu gibi Osmanlı Devleti ile ilgili gelişmelerde de titizlikle yürürlükte olduğunu anlıyoruz ${ }^{36}$. Dolayısıyla Metternich'in Osmanlı Devleti'ni yaşatmaya yönelik fikirlerinin karşısında duran Mehmet Ali Paşa taraftarlarının ve Philhellenlerin düşünceleri yazılı basında genellikle kendilerine yer bulamamışlardır. Uygulanan bu baskı liberal toplumun "Metternich Sistemi"ne duyduğu nefreti daha da perçinlemekle kalmamış, Osmanlı Devleti'nin savunucusu konumunda olan monarşiye duyulan nefret, Osmanlı Devleti'ne de yöneltilmiştir. Liberallerin gözünde oluşan tabloda "özgürlük savaşı veren Yunanları bastırmaya çalışan bir despot devlet başka bir despot devlet tarafından korunmaktadır". Dolayısıyla liberal Avrupa düşlerinde "Metternich Sistemi"ne yer olmadığı gibi "barbar"37 Osmanlılara da yer yoktur. ${ }^{38}$ Yani Gentz, Prokesch, Ottenfels gibi entellektüellerin fikirleri doğrultusunda şekillenen Metternich'in çabaları, aslında Monarşi ve Osmanlı karşıtlığını ve Yunan savunuculuğunu daha da güçlendirmekten ve farklı muhalifleri bir havuzda toplamış olmaktan başka bir fayda sağlayamamıştır.

\footnotetext{
${ }^{36}$ Steffen L. Schwarz, Despoten - Barbaren - Wirtschaftspartner. Die Allgemeine Zeitung und der Diskurs über das Osmanische Reich 1821-1840, Köln; Weimar, Viyana 2016, S. 101.

37 Jürgen Osterhammel, Die Entzauberung Asiens. Europa und die asiatischen Reiche im 18. Jahrhundert, Münih 1998, S 308.

${ }^{38}$ Ayrıntılı bilgi için: Schwarz, Despoten, S. 101-105.
}

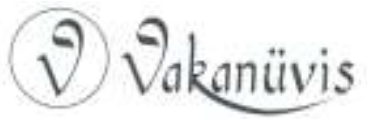


Ek 1: Mektup adetlerini gösterir tablo

\begin{tabular}{|c|l|}
\hline Gönderen - Alıcı & Mektup Adedi $^{39}$ \\
\hline $\begin{array}{c}\text { Prokesch'den Gentz'e (Osmanlı'da iken 1830'a } \\
\text { kadar / Avrupa'dan) }\end{array}$ & $71 / 57$ \\
\hline Prokesch'den Metternich'e (1825-1830) & 80 \\
\hline Metternich'den Prokesch'e & 25 \\
\hline Metternich'den Gentz'e (1824-1829) & 27 \\
\hline Ottenfels'den Gentz'e & 35 \\
\hline Ottenfels'den Prokesch'e (1824-1830) & $84^{40}$ \\
\hline Gentz'den Ottenfels'e (1823-1831) & 269 \\
\hline Gentz'den Prokesch'e & 124 \\
\hline Gentz'den Hammer'e & 5 \\
\hline
\end{tabular}

\section{Kaynakça}

Allgemeine Deutsche Biographie (ADB) C. 26, S. 631-645.

Karl Mendelssohn Bartholdy, "Geschichte Griechenlands. Von der Eroberung Konstantinopels durch die Türken im Jahre 1453 bis auf unsere Tage", C. 1, Paderborn 1870.

Daniel Bertsch, Proeksch von Osten, Anton Franz Graf, Neue Deutsche Biographie (NDB) C. 20, Berlin 2001, S. 739-740.

Daniel Bertsch, “Anton Prokesch von Osten (1795-1876). Ein Diplomat Österreichs in Athen und an der Hohen Pforte. Beitraege zur Wahrnehmung des Orients im Europa des 20. Jahrhunderts", Münih 2005.

Daniel Bertsch, "Der österreichische Diplomat Anton Prokesch von Osten (1795-1876) und das heilige Land", Sabina Rogge (Ed.) Zypern und der Vordere Orient im 19. Jahrhundert. Die Levante im Fokus von Politik und Wissenschaft der europäischen Staaten, Münster 2009, S. 43-62.

A. Breycha-Vauthier, Ottenfels-Gschwind, Franz Frh. von (1778-1851), Diplomat, Österreichische Biographische Lexikon 1815-1950, C. 7 (1977), S. 269.

${ }^{39} \mathrm{Bu}$ bölümde şahıslar arasındaki tüm mektuplaşmalardan ziyade, mektupların sadece Şark meselesine dair olanlarının sayıları verilmeye çalışılmıştır.

${ }^{40}$ http://www.archivinformationssystem.at/detail.aspx?ID=1121513

http://www.archivinformationssystem.at/detail.aspx?ID=3463632

http://www.archivinformationssystem.at/detail.aspx?ID=3463633

http://www.archivinformationssystem.at/detail.aspx?ID=3463634

http://www.archivinformationssystem.at/detail.aspx?ID=3463635

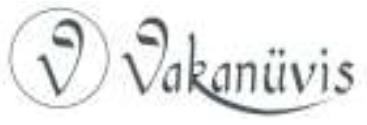


Friedrich von Gentz'in Mektup Arşivi [http://gentz-digital.ub.unikoeln.de/].

Joseph Freiherr von Hammer-Purgstall, „Erinnerungen aus meinem Leben“, [Hammer Hatıratı], Österreichische Akademie der Wissenschaften [Avusturya Bilimler Akademisi Arşivi].

Harald Heppner, "Hammer-Purgstall und die Orientfrage", Österreichische Osthefte, C. XXI., 1979. Viyana; Zürich, S. 89-96.

Harald Heppner, "Hammer Purgstall und österreichische Innenpolitik", Domus Austriae. Eine Festgabe für Hermann Wiesflecker zum 70. Geburtstag, Walter Höflechner; vb. (Ed.), Graz 1983, S. 210-215.

Walter Höflechner, Alexandra Wagner (Ed.), “Joseph von HammerPurgstall. Erinnerungen und Briefe", Version 1 201107: Briefe von 1790 bis Ende 1819, 3 C., Graz 2011. [http://gams.uni-graz.at/context:hp]

Peter Melichar, Metamorphosen eines treuen Dieners, Robert Hoffmann (Ed.), Bürger zwischen Tradition und Modernität, Wien; Köln; Weimar 1997, S.105-143.

Prince Richard Metternich, "Memoirs of Prince Metternich 1773-1835", Alexander Napier (Çev.), 5 C., Londra 1880-1882.

Richard Metternich-Winneburg (Ed.), “Aus Metternich's nachgelassenen Papieren". Geordnet und zusammengestellt von Alfons v. Klinkowström, C. I, Bölüm 1 Viyana 1880; C. I, Bölüm 2, Von der Geburt Metternich's bis zum Wiener Kongress 1773-1815; C. II, Bölüm 1, C. II, Bölüm 2, Friedens-Era 18161848, Viyana 1881.

Ariadni Moutafidou, "Anton Graf Prokesch von Osten: Philhellenismus und absolutistisches Staatsbild", Das Bild Griechenlands im Spiegel der Völker (17. bis 18. Jahrhundert), Evangelos Konstantinou (Ed.), Frankfurt am Main 2008, S. 203-218.

Jürgen Osterhammel, Die Entzauberung Asiens. Europa und die asiatischen Reiche im 18. Jahrhundert, Münih 1998.

Ritter von Prokesch A. Osten, Reise ins Heilige Land. Im Jahr 1829, Viyana 1831.

Anton Prokesch-Osten, "Betrachtungen über die orientalische Frage", Journal des österreichischen Lloyd, Triest 21. Haziran 1848.

Anton Freiherrn von Prokesch-Osten, "Geschichte des Abfalls der Griechen vom türkischen Reiche im Jahre 1821 und der Gründung des Hellenischen Königreiches. Aus diplomatischem Standpuncte", C. I, II, Viyana 1867.

Anton Grafen Prokesch-Osten (Ed.), "Zur Geschichte der orientalischen Frage. Briefe aus dem Nachlasse Friedrichs von Gentz", 1823-1829, Viyana 1877. 
Anton Grafen Prokesch-Osten (Ed.), Aus dem Nachlasse des Grafen Prokesch-Osten. Briefwechsel mit Herrn von Gentz und Fürsten Metternich, 2 C., Viyana 1881.

Prokesch von Osten, Graf Anton, Aus den Tagebüchern des Grafen Prokesch von Osten (1830-1834), Viyana 1909.

Michael Rohrschneider, Friedrich von Gentz (1764-1832) - ein Intellektueller avant la lettre? Beobachtungen anhand der Quellenpublikation "Gentz digital": Leben und Wirken, Kaynak: Gudrun Gersmann, Friedrich Jaeger, Michael Rohrschneider (Ed.), Virtuosen der Öffentlichkeit? Friedrich von Gentz (1764-1832) im globalen intellektuellen Kontext seiner Zeit, historicumestudies.net, URL: http://www.historicum-estudies.net/epublished/virtuosender-oeffentlichkeit/digital-intellectuals/friedrich-von-gentz-1764-1832-einintellektueller-avant-la-lettre-beobachtungen-anhand-derquellenpublikation-gentz-digital/leben-und-wirken/

Steffen L. Schwarz, "Despoten - Barbaren - Wirtschaftspartner. Die Allgemeine Zeitung und der Diskurs über das Osmanische Reich 1821-1840", Köln; Weimar, Viyana 2016.

Miroslav Sedivy', Metternich and the Ottoman reform movement, European Review of History: Revue européenne d'histoire, 18:4, 2011, S. 427441.

Georg Martin Thomas (Ed.), "Gesammelte Werke von Jakob Philipp Fallmerayer". C. I: Neue Fragmente aus dem Orient; C. II: Politische und Kulturhistorische Aufsätze, C. III: Kritische Versuche, Leipzig 1861.

Selçuk Ünlü, “Avusturya'lı Diplomat Anton Von Prokesch-Osten (17951876) ve Türkiye", Türk Dünyası Araştırmaları, 1984, C. 33, S. 57-67.

Karl Vocelka, Prokesch von Osten, Anton Gf., ÖBL C. 8, S. 301-302.

Constantin von Wurzbach, Biographisches Lexikon des Kaiserthums Oesterreich, Viyana 1856, C. 23, S. 349-356. 